Session 3420

\title{
Abstraction in Computer Network Education: A model based approach
}

\author{
G. Kohli, S. P. Maj, G. Murphy \& D. Veal \\ Edith Cowan University, Perth, WA, Australia
}

\begin{abstract}
Rapid developments in network technology have resulted in the inclusion of ACM/IEEE recommendations for Net-Centric computing as a part of the Computer Science Undergraduate Body of Knowledge. Accordingly ACM/IEEE networking curriculum now represents an increasingly significant component of Computer Science curriculum. Furthermore, relatively inexpensive equipment, such as switches and routers, and associated on-line vendor based curricula, such as CCNA, CCNP, are now readily available. This approach to network technology education requires an understanding of switch and router operation. However, an extensive analysis of educational materials in this area has indicated that these devices are typically treated as 'black boxes'. Such an approach may not be best suited to the promotion of learning as students are required to construct their own mental model of the internal operation of such devices and which may, or may not, be correct. To address this problem a state model has been designed for both switches and routers which allows complexity to be controlled and hence can be used as a basis for teaching both introductory and advanced courses. These models have been used as the pedagogical foundation for both undergraduate and postgraduate curricula in network technology and the results evaluated. Work to date suggests that these models strongly support student learning at all levels. A wide range of students were analysed and significantly students who had studied a number of networking units but had not been taught via these models scored lower than novice students taught using such models.
\end{abstract}

\section{Introduction}

Rapid developments in network technology have resulted in the inclusion of ACM/IEEE recommendations for Net-Centric computing within the Computer Science Undergraduate Body of Knowledge. Accordingly ACM/IEEE networking curriculum now represents an increasingly significant component of Computer Science curriculum. A central issue within computer network education is the hands-on laboratory-based approach versus the traditional in-call lecture-based approach. Traditionally, computer networks courses have not provided students with hands-on access to networking equipment and software. However, due to increasing popularity of vendor-based courses as components of undergraduate curricula, students now have the opportunity to study a more practical approach and hence program networking devices (switches, routers). Furthermore, many students are studying networking and internetworking 
from a non computing science and even a non-technical background. Such students need to comprehend a large number of new concepts within a short time span. In order to find potential solutions to these problems the authors have investigated modern educational theory regarding student understanding and conceptual changes. Diagrams can be employed as an aid to conceptual understanding. Thomas notes in respect to student difficulty in understanding concepts that: "The use of diagrammatic representation provides an alternative to just offering more words which may only compound their difficulties" 1 .

\section{Concepts and Constructivism}

Constructivism is a dominant theory in education. According to this theory students construct new ideas based upon their current/past knowledge. The students select and transform information, and make decisions that are dependent upon their present schema or mental models. It is important that educators are aware of student's mental models. According to Von Glasersfeld:

"Because there is no way of transferring meaning, i.e. concepts and conceptual structures, from one students head to another, teachers, who have the goal of changing something in students heads must have some notion of what goes on in these heads. Hence it would be seem necessary for a teacher to build up a model of the students conceptual world" 2 .

A student's mental model may or may not be correct and may require reorganisation to accord to accepted current practices and theory.

Changing a student's mental model requires conceptual reorganization, also known as conceptual change ${ }^{3}$. Before a conceptual change can take place, the naïve concepts that student possess need to be trapped. The process of making an existing mental model explicit is a crucial precursor to the cognitive restructuring process ${ }^{4}$. The authors are interested in mental models that map the structure of conceptions and forms of thinking that are used to describe how networking devices operate. Students studying internetworking are dealing with abstract and difficult topics that are not always clear. Setting the stage for conceptual change and learning by modeling is in itself a meaningful activity for gaining and refining understanding in complex scientific domains ${ }^{5}$. Conceptual change through building models have been advanced as tools to help student learning in science ${ }^{6}$, because educators have recognized that model-based reasoning can facilitate the development of mathematical-scientific understanding of the natural world ${ }^{7}$.

An important aspect of conceptual reorganization is abstraction. ACM states: "Enduring computing concepts include ideas that transcend any specific vendor, package or skill set... While skills are fleeting, fundamental concepts are enduring and provide long lasting benefits to students, critically important in a rapidly changing discipline". ${ }^{8}$ Abstraction has been a common theme in the context of aiding conceptual understanding ${ }^{9,10}$. It should be noted that different subjects have their own appropriate models at differing levels of abstraction dependant upon the area of use. Norman states that:

"A good representation captures the essential elements of the event, deliberately leaving out the rest. The critical trick is to get the abstractions right, to represent the important aspects and the 
unimportant. This allows everyone to concentrate upon the essentials without distraction from irrelevancies. Herein lie both the power and the weakness of representation: Get the relevant aspects rights, enhance people's ability to reason and think; get them wrong, and the representation is misleading, causing people to ignore critical aspects of the event or perhaps form misguided conclusions" 11 .

Despite the advantage of abstraction the authors were not able to identify any conceptual models of routers and switches used in networking education.

Accordingly a conceptual model of networking devices is needed that can be used as the pedagogical framework for teaching internetworking technologies to both introductory and advanced students. In addition a physical model is also required to describe the components, both hardware and software, that will be deployed into the target environment Physical models include all forms that have an external manifestation ${ }^{12}$. Physical models can assist students understanding of how networking devices may be connected via physical models, whilst conceptual models assist student understanding of the principles employed to enable devices to communicate with each other. A good model incorporates both approaches.

\section{A Switch and Router Model}

Two models have been developed - one for a switch and one for a router. Each model is based on a simple physical model thereby supporting initial student learning. However both models allow for the incorporation of progressively advanced conceptual features without the need for new models. Experience teaching network technology clearly indicates it is important to control complexity. Key concepts must be introduced in a controlled manner. The authors are developing such a model which has the requirements that it must not only be technically correct but also valid for different levels of complexity thereby supporting not only introductory but also more advanced concepts. This model also hides the complexity via the use of abstraction.

\subsection{A Switch Model}

In the first instance a switch is represented as a simple box with ports (interfaces). Each physical port is represented on the switch model (e.g. Fastethernet $0 / 1$ or Fa0/1). At the simplest level connectivity can be represented by internal connections between the ports within the switch. At a more complex level switches perform three main tasks: address learning; address forwarding and filtering; loop avoidance. A simple table can be incorporated into this diagram to teach how a switch learns and hence maps physical MAC addresses to ports i.e. address learning. This table can be used to teach how a switch establishes one to one connectivity (micro-segmentation) and hence performs address forwarding and filtering. 


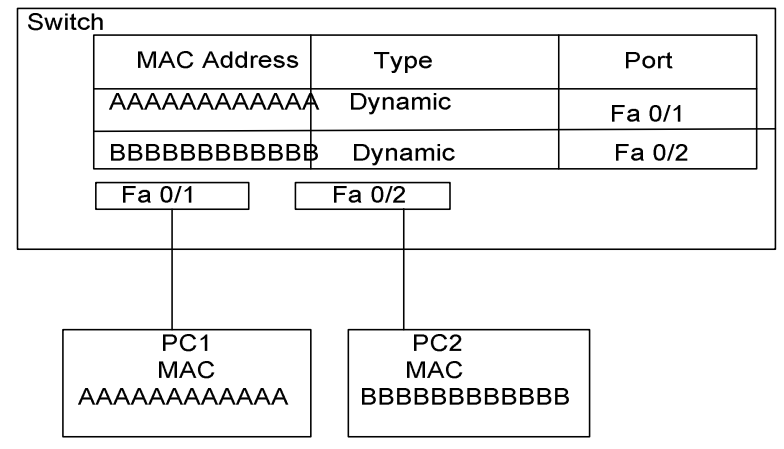

Figure 1: Switch Model

Similar a router model was also developed to represent the working of router and routing principles.

\subsection{A Router Model}

A PC is modeled as a device with a logical (IP) to physical (MAC address) Address Resolution Protocol (ARP) table and a Network Interface Card (NIC) table (IP address, Subnet mask and MAC address). Using this simple model it is possible to demonstrate simple PC to PC connectivity and the principles of ARP using a cross over cable. This exercise can further be enhanced by asking students to complete ARP (request) and ARP (reply) frames with the correct fields. The PC command "IPCONFIG" output directly maps onto these diagrams.

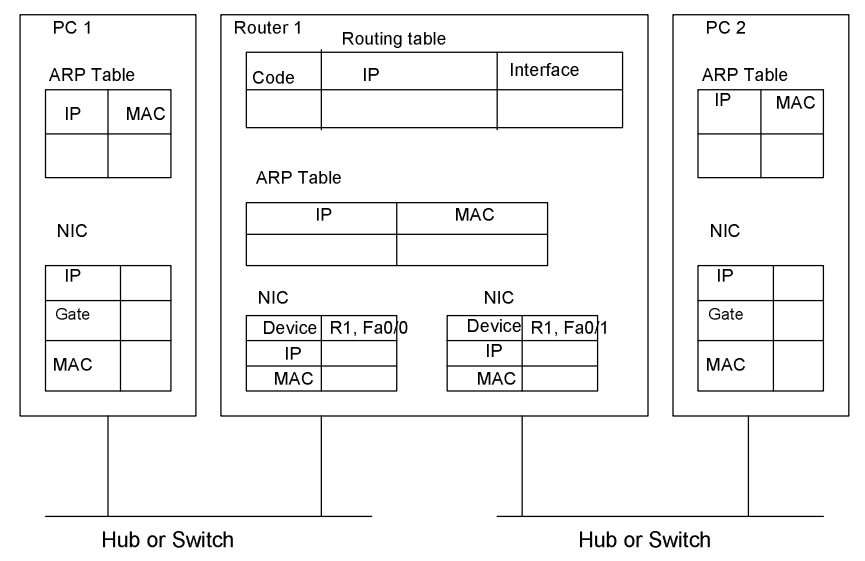

Figure 2: Router Model

A router is then modeled using the ARP and NIC table (as found in the PC) plus a routing table. Hence an incremental learning path is provided. The router commands "show arp" and "show ip route" can be used to in conjunction with the diagrams to show the state changes as networks are connected together. Again these diagrams form an integral part of the lectures. Workshop

Proceedings of the 2004 American Society for Engineering Education Annual Conference \& Exposition Copyright (C) 2004, American Society for Engineering Education 
exercises require students to work together on different networks and complete these diagrams using the output from router commands and "IPCONFIG" on the PCs. Again it is possible to enhance this exercise by requiring students to complete the fields for an IP packet as it traverses the different devices and hence observe how, due to encapsulation and de capsulation, only the frame addresses change.

\section{Analysis and Results}

Three separate groups of students participated in this study. One of the group were studying the CISCO Network Academy Program (CNAP) which includes both CISCO Certified Network associate (CCNA) ${ }^{13,14}$ and CISCO certified Network Professional (CCNP) $15,16,17$ at university. A standard university unit consists of 48 hours of staff contact time per 12 week semester. The CCNA curriculum represents the equivalent of two standard university units i.e. a total of 96 hours. Students must successfully complete the CCNA prior to enrolling on the CCNP course. The CCNP course consists of the equivalent of four university units i.e. a total of 192 hours. The second group was studying the CCNA at a local college. At this college the CCNA is taught as four modules each representing 40 hours of tuition i.e. a total of 160 hours. The local college awards Diplomas and Advance Diplomas but not Bachelor awards. The third group were enrolled on Masters Courses which were specifically designed for graduates with a non-IT undergraduate qualification i.e. conversion masters. For these postgraduate students there are two units (106 and 206) as a prerequisite chain. The first unit (106) is an introductory unit to computer and network technology, the second postgraduate unit (206) is dedicated to network technology. Half of 106 unit (24 hours) is allocated to computer technology and the other half ( 24 hours) is dedicated to network technology. The second postgraduate unit (206) is dedicated entirely to network technology.

Completion of both these units represents therefore a total of 72 hours of teaching in network technology. The vendor based curriculum students (CCNA and CCNP) were taught in the normal prescribed manner. The units for the postgraduate students were based on the models developed for switches and routers. Using these models the postgraduate students were taught the principles of switch and router operation. The models were used both in the lectures and in the workshops. All students were given a questionnaire designed to obtain their understanding of router operation. Hence in addition to standard questions such as, 'Briefly describe a router', students were given several details of different router configurations that they had to explain.

The CCNA students at both the local college and university showed a lack of understanding of router operation because of misconceptions as shown in (table 1). Such misconceptions are trapped by comparing the description given by an expert in that field to that given by a student. The CCNP students at both the local college and university performed only marginally better than all the CCNA students (table 1). On the other hand postgraduate students clearly showed a better understanding of router operation. They made fewer misconceptions and were able to correctly use a far wider range of technical terms (table 1). The postgraduate students arguably may have better study skills but had only completed 72 hours of network education. The CCNA students are exposed to 96 hours of staff contact time. It should also be noted at the beginning of the units, all students failed to demonstrate their mental model although they must have

possessed such a mental model. Postgraduate students, whose learning was based upon the state

Proceedings of the 2004 American Society for Engineering Education Annual Conference \& Exposition Copyright (C) 2004, American Society for Engineering Education 
models, demonstrated a comprehension of devices which more closely matched those of an expert when compared to students studying Cisco Network Academy Program (CNAP). Postgraduate students are arguably more mature and are likely to have better study skills than undergraduate students. However, one group of postgraduate students had completed only 24 hours of instruction in contrast to CCNP students who had successfully completed the CCNA (96 hours of instruction) and an additional semester of CCNP material (at least 96 hours of instruction).

\begin{tabular}{|c|c|c|c|c|}
\hline $\begin{array}{l}\text { CCNA } \\
\text { University (30) }\end{array}$ & CCNA TAFE (18) & $\begin{array}{l}\text { CCNP University } \\
\text { (9) }\end{array}$ & $\begin{array}{l}106 \text { University } \\
\text { (30) }\end{array}$ & $\begin{array}{l}206 \text { University } \\
\text { (18) }\end{array}$ \\
\hline Optimiser (3) & $\begin{array}{l}\text { Connects Networks } \\
\text { (9) }\end{array}$ & $\begin{array}{l}\text { Connects } \\
\text { Networks (2) }\end{array}$ & $\begin{array}{l}\text { Connects } \\
\text { Networks (3) }\end{array}$ & $\begin{array}{l}\text { Connects } \\
\text { Network (15) }\end{array}$ \\
\hline Road Map (2) & Layer 3 (4) & Layer $3(2)$ & Layer $3(9)$ & Layer $3(7)$ \\
\hline $\begin{array}{l}\text { Connects } \\
\text { Networks (3) }\end{array}$ & Best Path (4) & $\begin{array}{l}\text { Broadcast Domain } \\
\text { (2) }\end{array}$ & Best Path (3) & Best Path (1) \\
\hline Layer 3 (5) & Direct Traffic (4) & Control flow (1) & Direct traffic (2) & Direct traffic (2) \\
\hline Best Path (1) & No idea (10) & $\begin{array}{l}\text { Collision domain } \\
\text { (1) }\end{array}$ & $\begin{array}{l}\text { Broadcast domain } \\
\text { (5) }\end{array}$ & Routing table (2) \\
\hline Direct traffic (4) & & $\begin{array}{l}\text { Make decision on } \\
\text { IP (1) }\end{array}$ & Control flow (1) & $\begin{array}{l}\text { Make decision on } \\
\text { IP address (1) }\end{array}$ \\
\hline \multirow[t]{7}{*}{ No idea (4) } & & No idea (3) & Routing table (1) & Bridge gap (1) \\
\hline & & & $\begin{array}{l}\text { Packet switching } \\
\text { (1) }\end{array}$ & $\begin{array}{l}\text { Network } \\
\text { equipment (1) }\end{array}$ \\
\hline & & & $\begin{array}{l}\text { Collision domain } \\
\text { (3) }\end{array}$ & $\begin{array}{l}\text { Communicate } \\
\text { between VLAN } \\
\text { (1) }\end{array}$ \\
\hline & & & $\begin{array}{l}\text { Make decision on } \\
\text { IP address (2) }\end{array}$ & $\begin{array}{l}\text { Connects switch } \\
\text { (3) }\end{array}$ \\
\hline & & & $\begin{array}{l}\text { Network } \\
\text { Equipment (1) }\end{array}$ & ARP table (2) \\
\hline & & & $\begin{array}{l}\text { Connects switch } \\
\text { (1) }\end{array}$ & \\
\hline & & & Arp table (2) & \\
\hline
\end{tabular}

Table 1: Student Ideas of Router Operation

\section{Conclusions}

Constructivism is the dominant theory of conceptual understanding in modern educational theory. Understanding of students' conceptual models is of vital importance to educators because students use these models to facilitate their understanding. The authors have developed a state model as an aid to understanding the operation of routers and switches. Postgraduate students who were taught using these models demonstrated conceptual understanding of router and switch operation that was more in accordance with that of an expert in the field, than did the CNAP students who were not taught using this model. Further work is currently being undertaken to extend the scope of these models. Results to date clearly indicate that these models have had a significant impact upon student learning. The authors are developing this study further to obtain a better understanding of student's mental models. 


\section{Bibliography}

1. Thomas, R. Fewer Words, clearer picture: The value of a diagrammatic representation of ideas. in Third Biennial Communication skills in University education (CSUE). Fremantle, WA, Australia: Teaching and Learning Centre, Murdoch University, Murdoch, WA, Australia. (2000).

2. von Glasersfeld, E. and L.P. Steffe, Conceptual models in educational research and practice. Journal of Educational Thought, 25(2): 91 - 103. (1991).

3. Chi, M.T.H. and R.D. Roscoe, The processes and challenges of conceptual change. In M. Limon \& L. Mason (Eds.), Reconsidering conceptual change: Issues in theory and practice, 3-27. (2002)

4. Wichmann, A., J. Gottdenker, and D. Jonassen. Developing a Framework for Conceptual Change within Scientific Inquiry. In The 3rd IEEE International Conference on Advanced Learning Technologies (ICALT'03). (2003).

5. Milrad, M., M. Spector, and P. Davidsen, Model Facilitated Learning, in Learning and Teaching with Technology: Principles and Practices. Kogan Page Publishers: London, UK. (2002)

6. Edelson, D., D. Gordin, and R. Pea, Addressing the challenges of inquiry-based learning through technology and curriculum design. The Journal of the Learning Sciences, 8(3\&4): 391-450. (1999).

7. Lehrer, R., J. Horwath, and L. Schuable, Developing model-based reasoning. Interactive Learning Environments, 4(3): 219-231. (1994).

8. ACM. Computing curricula 2001 ACM/IEEE Joint Task Force Computer Science Final Report. 2001: ACM Press. (2001)

9. $\quad$ Ramsden, P., Learning to Teach in Higher Education. 1992, London: Routledge. (1992).

10. Staggers, N. and A. Forrcio, Mental models: Concepts for human-computer interaction research. International Journal of Man-Machine Studies, 38(4): 587-605. (1993).

11. Norman, D. R., Things That Make Us Smart. Peruses Books. (1993).

12. Sparks, G., An introduction to modelling software systems using the Unified Modelling Language. 2001.

13. Cisco, Cisco Networking Academy Program: First Year Companion Guide. (2 ed.). 2001, Indianapolis, IN USA: Cisco Press. 991. (2001).

14. Cisco, Cisco Networking Academy Program: Second Year Companion Guide. (2 ed.). 2002, Indianapolis, IN: Cisco Press. 718. (2002).

15. McGregor, M. and V. Amato, CCNP Cisco Networking Academy Program: Semester Five Companion Guide Advanced Routing. 2001, Indianapolis, IN: Cisco Press. (2001)

16. McGregor, M., CCNP Cisco Networking Academy Program: Remote Access Companion Guide. 2002, Indianapolis IN: Cisco Press. 492. (2002).

17. Lewis, W., CCNP Cisco Networking Academy Program: Multilayer Switching Guide. 2003, Indianapolis, IN: Cisco Press. 636. (2003).

\section{GUPREET KOHLI}

Gurpreet is a PhD student at Edith Cowan University with two years of experience in Lecturing and Developing Network and Data Communication units at Edith Cowan University. Gurpreet is currently investigating web services and capacity planning of e-business sites as part of his research at ECU.

\section{PAUL MAJ}

Associate Professor S. P. MAJ is a recognized authority in the field of industrial and scientific information systems integration and management. He is the author of a text book, 'The Use of Computers in Laboratory Automation', which was commissioned by the Royal Society of Chemistry (UK). His first book, 'Language Independent Design Methodology - an introduction', was commissioned by the National Computing Centre (NCC). Dr Maj has organized, chaired and been invited to speak at many international conferences at the highest level. He has also served on many national and international committees and was on the editorial board of two international journals concerned with the advancement of science and technology. As Deputy Chairman and Treasurer of the Institute of Instrumentation and Control Australia (IICA) educational sub-committee he was responsible for successfully 
designing, in less than two years a new, practical degree in Instrumentation and Control to meet the needs of the process industries. This is the first degree of its kind in Australia with the first intake in 1996. It should be recognized that this was a major industry driven initiative.

\section{GEORGE MURPHY}

George has a BSc degree from the Open University UK. He is a CCNA, CCNP and is a Cisco Certified Academy Instructor (CCAI). He now lectures on the CCNP units at ECU. He also lectures on the CCNP units at eCentral TAFE in Perth Western Australia. He has previously lectured on the CCNA, CCNP, Mathematics and Control Systems units at eCentral TAFE.

\section{DAVID VEAL}

David received an honours degree in theoretical physics from the University of York in England. After completing a Post Graduate Certificate in Education from the University of Keel after which he lectured in physics at South Devon College UK for 10 years. He now lives in Western Australia where he has taught computing, mathematics and physics at high school level. He now lectures in computing science at ECU in Perth, Western Australia. His areas of research include: Competency-based assessment techniques in computing science, modeling of computers and networks to aid student understanding, and Graphical User interfaces for the partially sighted. 